\title{
ELASTICIDADE DA DEMANDA DA CARNE SUÍNA BRASILEIRA EXPORTADA (1995-2013)
}

\author{
Laércio Juarez Melz* \\ Pascoal José Marion Filho** \\ Reisoli Bender Filho *** \\ Kelmara Mendes Vieira**** \\ Daniel Arruda Coronel ${ }^{* * * * *}$
}

RESUMO: O objetivo deste artigo foi estimar as elasticidades-preço e elasticidadecruzada da demanda de carne suína exportada entre janeiro de 1995 e junho de 2013. O período foi escolhido devido à estabilidade econômica gerada após a implantação do Plano Real. Foram coletadas séries mensais de quantidades exportadas, preços de exportação, preços internos das carnes de suínos, bovinos e frangos, além do Produto Interno Bruto (PIB) brasileiro e taxa de câmbio do dólar nos bancos de dados do Ministério do Desenvolvimento, Indústria e Comércio Exterior (MDIC) e do Instituto de Pesquisa Econômica Aplicada (IPEA). Foi estimada regressão por Mínimos Quadrados com Quebras. Pelo procedimento de Bai-Perron foi localizada quebra estrutural no mês de fevereiro de 2002. A quebra foi justificada pela alta dos insumos, milho e soja, seguida pela queda dos preços internacionais da carne suína. Antes da quebra, o preço externo da carne suína e o preço interno da carne bovina eram preditores da demanda. Após a quebra, os preditores passaram a ser os preços internos da carne bovina e de frango e a renda nacional. A direção do sinal na regressão indicou que a carne suína é complementar da carne bovina e substituta da carne de frango no mercado internacional.

PALAVRAS-CHAVE: Mercado Internacional; Quebras Estruturais; Suinocultura.

\footnotetext{
Doutorando em Administração (UFSM); Docente da Universidade do Estado de Mato Grosso (UNEMAT) Brasil; E-mail: laercio@unemat.br

*** Doutor em Economia Aplicada (ESALQ/USP); Docente do Programa de Pós-Graduação em Administração da Universidade Federal de Santa Maria (PPGA/UFSM), Brasil.

*** Doutor em Economia Aplicada pela Universidade Federal de Viçosa (UFV); Docente do Programa de Pós-Graduação em Administração da Universidade Federal de Santa Maria (PPGA/UFSM), Brasil.

**** Doutora em Administração (UFRGS); Docente do Programa de Pós-Graduação em Administração da Universidade Federal de Santa Maria (PPGA/UFSM), Brasil.

***** Doutor em Economia Aplicada (UFV); Docente do Programa de Pós-Graduação em Administração da Universidade Federal de Santa Maria (PPGA/UFSM), Brasil.
} 


\section{FLUCTUATION OF DEMAND OF EXPORTED BRAZILIAN PORK (1995-2013)}

ABSTRACT: Current assay estimates price fluctuations and cross-demand fluctuations of pork exported between January 1995 and June 2013, a period of economic stability due to the establishment of the Real Plan in Brazil. Monthly series of exported amounts, export prices, internal prices of pork, beef and chicken were harvested, coupled to the Brazilian GNP and exchange rates for the US dollar in data banks of the ministry of Development, Industry and External Commerce and of the Institute of Applied Economic research (IPEA). Regression by estimated Least Squares with Breaks and structural break was pinpointed by Bai-Perron procedures in February 2002. Break was due to price rise of corn and soybean, followed by fall in international prices of pork. External price of pork and the internal price of beef forecasted demand. After the break, predictors became the internal prices of beef and chicken and national income. Regression signal direction indicated that pork complements beef and substitutes chicken in the international market.

KEY WORDS: International Market; Structural Breaks; Pork.

\section{INTRODUÇÃO}

A carne suína é a mais consumida no mundo, mesmo com restrições em alguns países devido aos hábitos, às proibições religiosas e dogmáticas (GERVASIO, 2013). A despeito da crença de que carne suína é prejudicial à saúde, é uma carne magra e contém nutrientes semelhantes aos das demais carnes (RG NUTRI, 2013; VALLE, 2000; ABIPECS, 2013). Entre os principais países importadores mundiais, em 1995, a Alemanha era a maior, com 17,1\% de participação, seguida pelo Japão (14,5\%), Itália (12,6\%) e Rússia (11,4\%). Em 2011, estes países passaram a importar 9,4\% (Alemanha), 8,8\% (Japão e Itália) e 6,1\% (Rússia) das carnes suínas. Por outro lado, países como Hong Kong, México, Coreia do Sul e Polônia tiveram, respectivamente, aumentos de 58,2\%, 296\%, 357\% e 378\% de participação nas importações mundiais, entre 1995 e 2011.

Entre 1995 e 2012, algumas mudanças na composição dos principais exportadores aconteceram. A Dinamarca, que era o maior exportador em 1995, 
com $18,4 \%$ do mercado, teve decrescente participação, deixando seu posto para os Estados Unidos, em 2008, e para a Alemanha em 2009. Este país passou a ser o maior exportador mundial de carne suína, mantendo-se na posição até 2011, com 15,9\% do mercado. Estados Unidos apresentaram participação crescente no cenário, como segundo no ranking, entre 2008 e 2011 (14,6\%). O Brasil era o nono colocado no ranking em 1995, com 0,8\% de participação. Sua maior participação aconteceu em 2002, com 6,9\% do mercado. Em 2011, o país participava de 4,5\% das exportações mundiais. Comparando o crescimento percentual de participação, o Brasil teve 464,9\% de acréscimo no volume vendido, Alemanha 319,3\%, Estados Unidos 131,5\% e Dinamarca -41,2\%, entre 1995 e 2012. Isso demonstra que, no mercado de carne suína, ainda há potencial de exportação pelo Brasil (FAO, 2013).

As exportações brasileiras, em 1995, foram destinadas, principalmente, para Hong Kong, Argentina e Uruguai, com 58,2\%, 27,6\% e 6,0\%, respectivamente. Em 2012, os principais importadores da carne suína brasileira foram Ucrânia, Rússia e Hong Kong, participando com 24,65\%, 22,59\% e 21,26\%, respectivamente. Rússia passou a importar o produto do Brasil, de forma expressiva apenas em 2000 (18,5\%). Os preços médios de exportação da carne suína foram de US\$1,96/kg e a quantidade média exportada entre 1995 e 2013 foi de 28 milhões de toneladas (MDIC, 2013).

Economicamente, é consolidada a teoria de que existe relação entre preços e renda. Esta relação, quando medida em termos de sensibilidade do consumidor, denomina-se de elasticidade ${ }^{1}$. Porém, é convergente o entendimento de que não somente os preços determinam a demanda, mas também outras variáveis como preços de outras carnes, taxa de câmbio, barreiras tarifárias e não tarifárias. Diversos estudos têm buscado compreender melhor essas relações ao longo dos anos, como: Henneberry e Mutondo (2007), Hupková e Bielik (2009), Gallet (2010; 2012), entre outros. Resende Filho et al. (2012) verificaram que, no Brasil, as carnes têm demanda inelástica e são bens substitutos entre si, sendo a principal preferência a carne bovina, seguida pelo frango e, em último, a carne suína.

Considerando que os substitutos mais próximos são as carnes de frango e bovina e que o Brasil tem passado por período de estabilidade econômica desde 1995, o objetivo principal deste artigo é verificar o impacto dos preços e da renda

\footnotetext{
${ }^{1}$ A elasticidade reflete o percentual de variação da demanda em função do percentual de variação no preço, na renda (PINDICK; RUBINFELD, 2006; VARIAN, 2010).
} 
externa nas exportações de carne suína no período pós-estabilização de preços. Sendo o mercado externo analisado, há necessidade de verificar-se o impacto da variação cambial e preços internos nesta demanda, como objetivo secundário.

Gallet $(2010 ; 2012)$ e Resende Filho et al. (2012) ressaltam a importância de estudos sobre elasticidade da demanda em diferentes regiões do mundo como instrumento de auxílio na formulação de políticas públicas e de estratégias empresariais para incentivo ao consumo de carnes. Resende Filho et al. (2012) apontam a escassez de estudos quantitativos sobre demanda agregada de carnes no Brasil. Mesmo sendo um tema importante, não foi realizada pesquisa para estabelecer relações entre preços e demanda de carnes brasileiras no mercado internacional, especialmente de carne suína. Pretende-se que esta seja a contribuição deste artigo.

$\mathrm{O}$ artigo está estruturado em mais quatro seções. Na seção dois é apresentado o modelo teórico e as evidências empíricas sobre o tema. O método utilizado para estimação da elasticidade preço cruzada, as fontes dos dados e testes dos pressupostos são apresentados na seção três. A seção quatro inclui a apresentação e a discussão dos resultados obtidos. A seção cinco oferece as considerações finais com as limitações e sugestões de futuras pesquisas.

\section{MATERIAL E MÉTODOS}

\subsection{MODELO TEÓRICO DE ELASTICIDADE}

A análise da demanda é importante para empresas e governos. Para as empresas, a previsão da demanda auxilia na determinação da melhor alocação dos recursos para produção de determinado bem de forma a maximizar o lucro. Para os governos, a previsão da demanda tem papel de estimar o impacto das políticas públicas na demanda dos bens (GALLET, 2012; RESENDE FILHO et al., 2012).

Partindo do pressuposto de que os indivíduos procuram otimizar suas decisões, haveria um limite de preços que o consumidor estaria disposto a pagar. Os consumidores, segundo Pindick e Rubinfeld (2006), têm limitações financeiras e, por isso, com base em suas preferências, maximizam o próprio bem-estar optando por comprar algumas unidades de um bem e, em contrapartida, adquirir menos de 
outro. Em termos percentuais, a elasticidade preço é definida como a variação da demanda causada pela variação nos preços de determinado bem, conforme equação 1 (VARIAN, 2010).

$$
E_{p}=\frac{\Delta Q / Q}{\Delta P / P}=\left(\frac{P}{Q}\right)\left(\frac{\Delta Q}{\Delta P}\right)
$$

Na equação, $P$ é o preço e $Q$ é a quantidade de um determinado bem. $\Delta Q / Q$ reflete a variação percentual da quantidade demandada e $\Delta P / P$ é a variação percentual do preço entre dois períodos. A demanda pode ser classificada, a partir do resultado desta formulação, em elástica, unitária ou inelástica. A demanda é inelástica quando aumentos de preço ocasionam apenas uma pequena variação na quantidade demandada, então, o resultado da equação é menor que $1\left(E_{p}<1\right)$, em números absolutos. Demanda unitária acontece quando o percentual de variação das quantidades é exatamente igual ao percentual de variação dos preços $\left(E_{p}=1\right)$ e demanda elástica ocorre quando o resultado é maior que $1\left(E_{p}>1\right)$ (PINDICK; RUBINFELD, 2006; VARIAN, 2010).

Quanto maior for a elasticidade preço da demanda de um produto, permanecendo a renda constante, maior sua propensão à substituição do bem por outro (FERGUSON, 1989). Pindick e Rubinfeld (2006) afirmam que alterações nos preços de bens relacionados também afetam a demanda. Nessa linha, os bens são substitutos quando um aumento no preço de um deles leva a um aumento na quantidade demandada do outro. Essa relação é chamada de elasticidade preço cruzada e pode ser demonstrada pela equação 2, apresentada por Pindick e Rubinfeld (2006).

$$
\log (Q)=a-b \log (P)+b_{2} \log \left(P_{2}\right)+c \log (I)
$$

em que

$\log (Q): \operatorname{logaritmo~da~variação~na~quantidade~demandada~}(\log (\Delta Q / Q))$;

$a$ : intercepto da curva da demanda; 
$b \log (P): \operatorname{logaritmo~da~variação~de~preço~do~bem~}(\log (\Delta P / P))$;

$\mathrm{b}_{2} \log \left(\mathrm{P}_{2}\right)$ : logaritmo da variação do preço do bem substituto ou complementar ( $\left.\log \left(\Delta \mathrm{P}_{2} / \mathrm{P}_{2}\right)\right) ; \mathrm{e}$

$c \log (I): \operatorname{logaritmo}$ da variação na renda $(\log (\Delta I / I))$.

Observa-se que a quantidade demandada, como variável dependente, e os preços do bem e seus substitutos, além da renda. Greene (2002) afirma que os modelos com logaritmos permitem uma interpretação dos coeficientes na forma de percentual. Pindick e Rubinfeld (2006, p. 118) afirmam que "quando $b_{2}$, que é a elasticidade de preço cruzado, for positiva, os dois bens serão substitutos, quando $b_{2}$ for negativa, eles serão complemento um do outro".

Além de incluir as variáveis de preço e renda, a função de elasticidade da demanda internacional deve considerar variáveis relacionadas a este mercado. Resende Filho et al. (2012) afirmam que outras variáveis, além do preço e gasto afetam a demanda por carnes, devendo ser incluídas no modelo. Nesse sentido, pode-se verificar que Barros, Bacchi e Burnquist (2002) utilizaram como variável dependente a quantidade exportada e, como independentes, os preços no mercado externo e interno, a taxa de câmbio real e a renda nacional real. Sendo a função de exportação:

$$
S^{x}=f(P e, P i, E, R)
$$

onde:

$S^{x}$ : quantidade exportada por unidade de tempo;

$P e$ : preço recebido pelas exportações;

$P i$ : preço recebido no mercado interno pelo produto;

$E$ : taxa de câmbio real efetiva; e

$R$ : renda nacional real.

O impacto da variação da renda na demanda por um bem é chamado de elasticidade-renda da demanda. Conforme Varian (2010), a elasticidade-renda pode 
ser medida pela equação 4 :

$$
E_{r}=\frac{\Delta Q / Q}{\Delta R / R}
$$

em que:

$\triangle Q / Q$ é a variação percentual nas quantidades;

e $\Delta R / R$ é a variação percentual na renda.

Quando o resultado da equação é $1\left(E_{r}=1\right)$ é considerado um bem normal, quando é menor que $1\left(E_{r}<1\right)$ é um bem inferior, e quando maior que $1\left(E_{r}>1\right)$ é um bem superior (VARIAN, 2010). Isso indica que, quando o bem é inferior, seu consumo é necessário sendo consumido por pessoas em todas as faixas de renda. Ao contrário, um bem superior somente será consumido quando as faixas de renda são maiores. Quanto maior esse coeficiente, maior a renda necessária para o consumo do bem.

\subsection{MÍNIMOS QUADRADOS COM QUEBRAS}

Foi adotado o modelo de Mínimos Quadrados com Quebras Estruturais, sugerido por Bai e Perron (1998; 2003). Esse modelo foi escolhido porque admite que as relações entre as variáveis independentes e a dependente são dinâmicas ao longo do tempo. O modelo utiliza um algoritmo baseado em programação dinâmica no qual são estimados modelos com períodos diferentes, minimizando a soma dos quadrados dos resíduos. Bai e Perron (2003) consideram que a regressão pode apresentar $m$ quebras, sendo:

$$
y_{t}=x_{t}^{\prime} \beta+z_{t}^{\prime} \delta_{j}+\mu_{t} \quad t=T_{j-1}+1, \ldots, T_{j}
$$

Para $j=1, \ldots, m+1$. Neste modelo, $y_{t}$ é a variável dependente observada em um tempo $t ; x_{t}(p+1)$ e $z_{t}(q+1)$ são vetores de covariância e $\beta$ e $\delta_{j}(j=1$, $\ldots, m+1)$ são os vetores dos coeficientes; $\mu_{t}$ é um distúrbio no tempo $t$. As quebras 
estruturais $\left(T_{1}, \ldots, T_{m}\right)$ são tratadas como desconhecidas, utilizando-se a convenção de que $T_{0}=0$ e $T_{m}+1=T$. Quando um dos $\beta$ 's não está sujeito a mudanças ao longo da amostra completa há quebra parcial. Quando $p=0$ acontece uma quebra estrutural pura, neste caso, todos os coeficientes dos regressores são alterados. A variância do erro $\mu_{t}$ não precisa ser constante, desde que as quebras de variância sejam coincidentes com as quebras nos parâmetros da regressão (BAI; PERRON, 2003). A equação (5) pode ser expressa em forma de matriz da seguinte forma:

$$
Y=X \beta+\bar{Z} \delta+U
$$

em que:

$Y=\left(y_{1}, \ldots, y_{T}\right)^{\prime}, X=\left(x_{1}, \ldots, x_{T}\right)^{\prime}, U=\left(\mathrm{u}, \ldots, u y_{T}\right)^{\prime}$,

$\delta=\left(\delta_{1}^{\prime}, \delta_{2}^{\prime}, \ldots, \delta_{m+1}^{\prime},\right)^{\prime}$ e $\bar{Z}$ é a matriz com diagonal $\mathrm{Z}$ no $T_{1}, \ldots, T_{m}$. Para cada $m$ quebra $\left(T_{1}, \ldots, T_{m}\right)$ uma regressão por Mínimos Quadrados Ordinários (MQO) associada é obtida pela minimização dos quadrados dos resíduos (equação 7).

$$
(Y-X \beta-\bar{Z} \delta)^{\prime}(Y-X \beta-\bar{Z} \delta)=\sum_{i=1}^{m+1} \sum_{t=T_{i-1}+1}^{T_{i}}\left[y_{t}-x_{t}^{\prime} \beta-z_{t}^{\prime} \delta_{i}\right]^{2}
$$

na qual $\hat{\beta}\left[\left\{T_{j}\right\}\right]$ e $\hat{\delta}\left[\left\{T_{j}\right\}\right]$ representam as estimativas baseadas em $m$ quebras $\left(T_{1}, \ldots\right.$ ,$T_{m}$ ) denotadas por $\left\{T_{j}\right\}$. Substituindo estes na função objetiva e denotando a soma resultante do quadrado dos resíduos como $S_{T}\left(T_{1}, \ldots, T_{m}\right)$, as quebras estimadas são $\left(\widehat{T}_{1}, \ldots, \widehat{T}_{m}\right)$ é tal que $\left(\widehat{T}_{1}, \ldots, \widehat{T}_{m}\right)=\operatorname{argmin}_{T_{1}, \ldots, T_{m}} S_{t}\left(T_{1}, \ldots, T_{m}\right)$ na qual a minimização é considerada em todas as quebras $\left(T_{1}, \ldots, T_{m}\right)$ como $T_{i}-T_{i-1} \geq q^{2}$ . Os parâmetros da regressão são estimados de forma associada às $m$ quebras $\left\{T_{j}\right\}$ , como que $\hat{\beta}=\hat{\beta}\left[\left\{T_{j}\right\}\right]$ e $\hat{\delta}=\hat{\delta}\left[\left\{T_{j}\right\}\right]$. As quebras são testadas sequencialmente iniciando-se o teste entre 0 versus 1 , em seguida, 1 versus 2 quebras e avançando até o que as $m$ quebras ( $m$ versus $m+1$ quebras) atinjam o ponto ótimo, no qual minimiza-se a soma dos quadrados dos resíduos (SSR).

Os intervalos entre quebras são chamados de regimes $(j)$. Portanto, para cada quebra estrutural será somado 1 para saber o número de regimes. Por exemplo, 
quando existe 1 quebra estrutural, há 2 regimes, um antes e outro após a quebra. Quando existem $m$ quebras, existem $m+1$ regimes $(j=m+1)$.

\subsection{MODELO EMPÍRICO}

Considerando que a demanda de carne suína brasileira depende de seu preço, dos preços das carnes de frango e bovina, tanto no mercado interno, quanto internacional e, ainda, que há impacto do câmbio e da renda, o modelo empírico utilizado é:

$$
\begin{aligned}
\log \left(Q_{-} S_{t j}\right)= & \beta_{0}+\beta_{1} \log \left(P E_{-} S_{t j}\right)+\beta_{2} \log \left(P E_{-} B_{t j}\right)+\beta_{3} \log \left(P E_{-} F_{t j}\right)+\beta_{4} \log \left(P I S_{t j}\right) \\
& +\beta_{5} \log \left(P l_{-} B_{t j}\right)+\beta_{6} \log \left(P I_{-} F_{t j}\right)+\beta_{7} \log \left(R_{t j}\right)+\beta_{8} \log \left(E_{t j}\right)+\varepsilon_{t j}
\end{aligned}
$$

em que:

$Q \_S$ : quantidade exportada de suínos em quilogramas/mês;

$P E \_S$ : preço médio mensal recebido, em dólares americanos (Free On Board - FOB), por quilograma de carne suína exportada, obtido dividindo-se o valor exportado pela quantidade exportada em quilogramas;

$P E B$ : preço médio mensal recebido, em dólares americanos (FOB), por quilograma de carne bovina exportada, obtido dividindo-se o valor exportado pela quantidade exportada em quilogramas;

$P E_{-} F$ : preço médio mensal recebido, em dólares americanos (FOB), por quilograma de carne de frango exportada, obtido dividindo-se o valor exportado pela quantidade exportada em quilogramas;

PI_S : preço médio mensal da carne suína para atacado em São Paulo, cotado em reais e deflacionado pelo Índice Geral de Preços (IGP-DI), a preços constantes;

$P I \_B$ : preço médio mensal da carne bovina para atacado em São Paulo, cotado em reais e deflacionado pelo IGP-DI, a preços constantes;

PI_F : preço médio mensal da carne de frango para atacado em São Paulo, cotado em reais e deflacionado pelo IGP-DI, a preços constantes;

$R$ : PIB mensal real do Brasil;

$E$ : taxa de câmbio real efetiva média mensal (dólar comercial para venda); 
$\varepsilon$ : o termo de erro aleatório com distribuição normal, isto é, média zero e variância constante;

$t$ : período de tempo em meses;

$j:$ regimes de quebras estruturais.

A partir da literatura, as relações são esperadas entre as variáveis são discutidas no Quadro 1.

Quadro 1. Relação esperada das variáveis independentes com a variável dependente (Quantidade de Suínos Exportada)

\begin{tabular}{|l|c|c|l|}
\hline Variável & Nome da variável & $\begin{array}{c}\text { Relação } \\
\text { Esperada }\end{array}$ & \multicolumn{1}{|c|}{ Referências } \\
\hline$P E_{-} S$ & $\begin{array}{c}\text { Preço Externo } \\
\text { Suíno }\end{array}$ & $<$ & $\begin{array}{l}\text { Resende Filho et al. (2012); Hovhannisyan e } \\
\text { Gould (2010). }\end{array}$ \\
\hline$P E_{-} B$ & $\begin{array}{c}\text { Preço Externo } \\
\text { Bovino }\end{array}$ & $><$ & $\begin{array}{l}\text { Resende Filho et al. (2012); Hovhannisyan e } \\
\text { Gould (2010); Varian (2010). }\end{array}$ \\
\hline$P E_{-} F$ & $\begin{array}{c}\text { Preço Externo } \\
\text { Frango }\end{array}$ & $><$ & $\begin{array}{l}\text { Resende Filho et al. (2012); Hovhannisyan e } \\
\text { Gould (2010). }\end{array}$ \\
\hline$P I_{-} S$ & $\begin{array}{c}\text { Preço Interno } \\
\text { Suíno }\end{array}$ & $>$ & Krugman e Obstfeld (2001). \\
\hline$P I \_B$ & $\begin{array}{c}\text { Preço Interno } \\
\text { Bovino }\end{array}$ & $><$ & Krugman e Obstfeld (2001); Varian (2010). \\
\hline$P I \_F$ & $\begin{array}{c}\text { Preço Interno } \\
\text { Frango }\end{array}$ & $><$ & Krugman e Obstfeld (2001); Varian (2010). \\
\hline$R$ & Renda & $>$ & $\begin{array}{l}\text { Resende Filho et al. (2012); Hovhannisyan e } \\
\text { Gould (2010). }\end{array}$ \\
\hline$E$ & Câmbio & $>$ & Krugman e Obstfeld (2001). \\
\hline
\end{tabular}

Fonte: Elaborado pelos autores.

Nota: PE_B é o Preço Externo do Bovino; PE_F é o Preço Externo do Frango; PE_S é o Preço Externo do Suíno; PI_S é o Preço Interno do Suínō; PI_B é o Preço Interno do Bovino; PI_F é o Preço Interno do Frango; R é a Renda; e E é a taxa de câmbio.

Em Pindick e Rubinfeld (2006), quando o regressor da elasticidade preço cruzada apresentar sinal positivo, significa que os bens são substitutos, quando o sinal for negativo, eles são complementares. Caso os bens sejam complementares à 
carne suína exportada, sua relação será negativa com a demanda, caso sejam bens substitutos sua relação será positiva. Quanto à renda, interpreta-se o bem como inferior, normal ou superior, quando seu coeficiente é menor, igual ou maior que a unidade, respectivamente.

\subsection{TESTES ECONOMÉTRICOS: PROPRIEDADES DAS SÉRIES E AJUSTAMENTO DO MODELO}

Para que o modelo de regressão seja suficientemente explicativo é preciso cumprir certos pressupostos (GUJARATI; PORTER, 2011). Inicialmente, para verificar a estacionariedade das variáveis realizou-se o teste de raiz unitária de Dickey-Fuller Aumentado - ADF (GREENE, 2002). Testa-se a hipótese nula de que há raiz unitária, assim se a série temporal é não estacionária, possui uma tendência temporal, por meio da equação (9):

$$
y_{t}=\mu+\beta t+\gamma y_{t-1}+\sum_{j=1}^{p} \gamma_{j} \Delta y_{t-j}+\varepsilon_{t}
$$

na qual:

$y$ : é a variável dependente;

$\mu$ : é a constante;

t: é o tempo;

$j$ : é o número de defasagens de tempo;

$p$ : é o número máximo de defasagens para somatória.

Na sequência, foi estimado o teste Engle-Granger para testar cointegração entre as séries. Engle e Granger (1987) afirmam que duas ou mais séries são cointegradas de ordem $d, b$, denotadas por $x_{t} \sim C I(d, b)$, se todos os componentes de $x_{t}$ são $I(d)$, existe um vetor $\alpha(\neq 0) \operatorname{com} z_{t}=\alpha^{\prime} x_{t} \sim I(d-b), b>0$. O vetor $\alpha$ é chamado de cointegrado quando rejeita-se a hipótese da existência de raiz unitária nos resíduos de uma regressão, confirmando estabilidade na relação de longo prazo entre as séries.

Para testar a normalidade dos resíduos utilizou-se o teste Jarque-Bera, 
conforme Gujarati e Porter (2011). Neste caso a hipótese nula é de que existe uma distribuição normal. Para testar a homocedasticidade foi realizado o teste de White, sob hipótese nula de ausência de heterocedasticidade (WHITE, 1980). Como medida preventiva, a regressão foi estimada com erros padrão robustos para heterocesdaticidade de White (GUJARATI; PORTER, 2011). Este procedimento consiste em utilizar os resíduos para corrigir a variância dos coeficientes de uma regressão, para corrigir o problema. Para detectar presença de autocorrelação, foi utilizada a estatística Durbin-Watson (DURBIN; WATSON, 1950; 1951). A hipótese nula de nenhuma autocorrelação não é rejeitada quando os valores da estatística $d$ ficam dentro de um intervalo tabulado (GUJARATI; PORTER, 2011).

\subsection{FONTES DOS DADOS}

Os dados de exportação e preços externos foram obtidos no banco de dados Aliceweb do Ministério do Desenvolvimento, Indústria e Comércio Exterior (MDIC, 2013). As séries foram mensais, correspondendo aos meses de janeiro de 1995 a junho de 2013, totalizando 222 observações. O ano inicial foi escolhido por ser o primeiro ano pós Plano Real. Foram agregados os produtos de carne exportados pelo Brasil nos grupos Bovino, Suíno e Frango (Quadro 2).

Quadro 2. Composição dos agregados de carnes

(continua)

\begin{tabular}{|c|c|l|}
\hline Agregado & NCM & Descrição \\
\hline \multirow{4}{*}{ Bovino } & 0202.10 .00 & Carcaças e meias-carcaças de bovino, congeladas. \\
\cline { 2 - 4 } & 0202.20 .10 & Quartos dianteiros não desossados de bovino, congelados. \\
\cline { 2 - 4 } & 0202.20 .20 & Quartos traseiros não desossados de bovino, congelados. \\
\cline { 2 - 4 } & 0202.20 .90 & Outras peças não desossadas de bovino, congeladas. \\
\cline { 2 - 4 } & 0202.30 .00 & Carnes desossadas de bovino, congeladas. \\
\cline { 2 - 4 } & 0201.30 .00 & Carnes desossadas de bovino, frescas ou refrigeradas. \\
\hline
\end{tabular}


(conclusão)

\begin{tabular}{|c|c|c|}
\hline \multirow{4}{*}{ Frango } & 0207.13 .00 & Pedaços e miudezas, de galos/galinhas, frescos/refriger. \\
\hline & 0207.14 .00 & Pedaços e miudezas, comest. de galos/galinhas, congelados. \\
\hline & 0207.11 .00 & Carnes de galos/galinhas, n/cort. pedaços, frescas/refrig. \\
\hline & 0207.12 .00 & Carnes de galos/galinhas, n/cortadas em pedaços, congel. \\
\hline \multirow{6}{*}{ Suíno } & 0203.11 .00 & Carcaças e meias-carcaças de suíno, frescas ou refriger. \\
\hline & 0203.12 .00 & Pernas, pas, etc. não desossad.de suíno, frescos ou refrig. \\
\hline & 0203.19 .00 & Outras carnes de suíno, frescas ou refrigeradas. \\
\hline & 0203.21 .00 & Carcaças e meias-carcaças de suíno, congeladas. \\
\hline & 0203.22 .00 & $\begin{array}{l}\text { Pernas, pas e pedaços não desossados de suíno, } \\
\text { congelados. }\end{array}$ \\
\hline & 0203.29 .00 & Outras carnes de suíno, congeladas. \\
\hline
\end{tabular}

Fonte: Elaborado pelos autores com dados do MDIC (2013).

O Produto Interno Bruto (PIB) brasileiro foi obtido no banco de dados do IPEA (2013) e atualizado pelo Índice Geral de Preços - Distribuição Interna (IGP-DI), com base em agosto de 2013. Os preços internos das carnes em séries mensais para atacado na cidade de São Paulo foram obtidos no mesmo banco de dados.

\section{RESULTADOS E DISCUSSÃO}

O comportamento das séries, em nível, pode ser observado na Figura 1. Um exame visual da quantidade de carne suína exportada (Q_S) indica que houve mudança de comportamento após 2002, aproximadamente, com maiores variações mensais em um nível superior. Verifica-se um período de depressão nos preços externos dos três tipos de carnes (PE_S, PE_B e PE_F) em 2003. Por sua vez, os preços internos da carne suína apresentam instabilidade em todo o período, com aparente tendência decrescente. A carne bovina teve períodos de baixa no atacado brasileiro, entre 2005 e 2007. A carne de frango, assim como a suína, apresenta tendência de queda em termos de preços internos, sendo que seu menor preço foi atingido em 2006. 

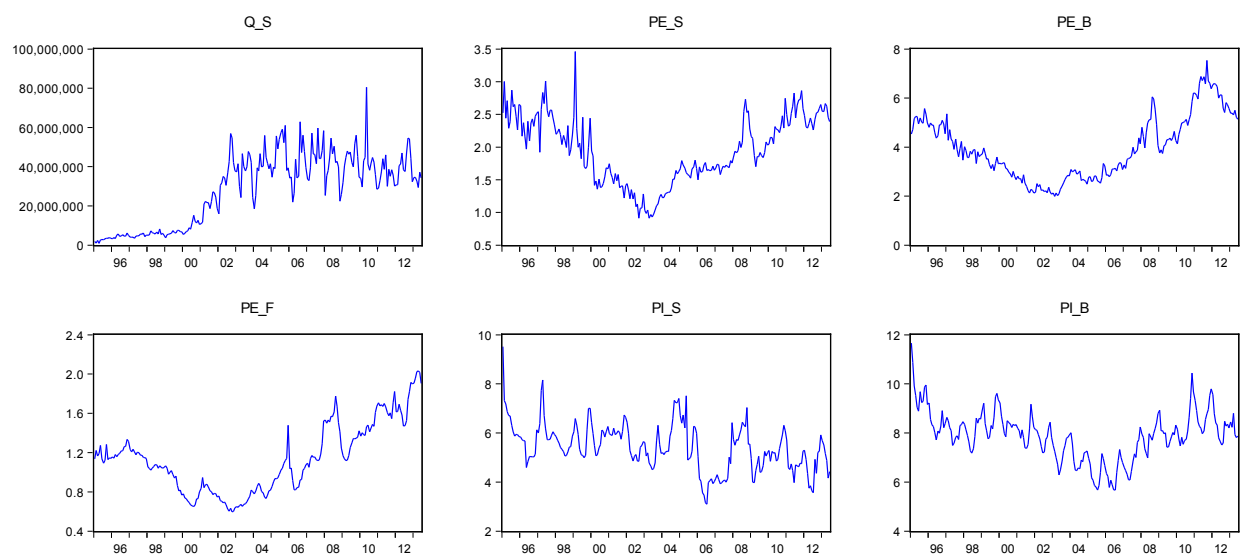

PIF

$\mathrm{R}$
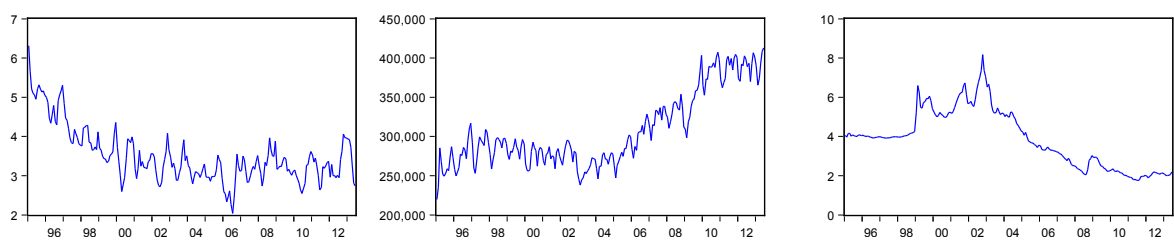

Notas: Q_S é a Quantidade Exportada (em quilogramas); PI_B é o Preço Interno do Bovino (em R\$/ $\mathrm{kg}$ ); PI_F é o Preço Interno do Frango (em R\$/kg); PD_S é o Preço Interno do Suíno (em R\$/kg); PE_B é o Preço Externo do Bovino (em US\$/kg); PE_F é o Preço Externo do Frango (em US\$/kg);

PE S é o Preço Externo do Suíno (em US\$/kg); R é a Renda representada pelo PIB do Brasil (em Milhões de R\$); e E é a taxa de câmbio em R\$/US\$. Os preços em R foram atualizados pelo IGP-DI de agosto de 2013.

Figura 1. Evolução dos valores das variáveis, jan./1995 a jun./2013.

Fonte: Dados da pesquisa (2013).

Enquanto os preços das carnes tendem à redução, a renda brasileira $(\mathrm{R})$, representada pelo PIB, cresceu entre 1995 e 2013. Quanto ao câmbio (E), houve um pico em 2003, seguido por quedas sucessivas. As variações bruscas observadas nas séries sugerem a existência de uma quebra estrutural entre 2002 e 2003.

\subsection{TESTES SOBRE PROPRIEDADES DOS DADOS}

O teste de Dickey-Fuller Aumentado (ADF) das séries em nível e em logaritmo demonstra que elas possuem raiz unitária, não sendo estacionárias. Porém, em primeira diferença o teste $\mathrm{ADF}$ indicou que as variáveis são estacionárias (ver Tabela 1). 
Tabela 1. Teste de Dickey-Fuller Aumentado para raiz unitária

\begin{tabular}{|c|c|c|c|c|c|c|c|c|c|c|}
\hline $\begin{array}{c}\text { Variáveis } \\
\text { em }\end{array}$ & Mundo & Q_S & PE_S & PE_B & PE_F & PD_S & PD_B & PD_F & $\mathbf{R}$ & E \\
\hline \multirow{3}{*}{ Nível } & $\mathrm{ADF}$ & $-2,787$ & $-1,625$ & $-1,235$ & $-0,627$ & 1,883 & 328 & 804 & 249 & $-1,966$ \\
\hline & $p$-valor & 0,062 & 0,468 & 0,659 & 0,861 & 0,340 & 0,999 & 0,378 & 0,975 & 0,302 \\
\hline & $\begin{array}{c}\text { crítico } \\
(5 \%)\end{array}$ & $-2,874$ & $-2,875$ & $-2,874$ & $-2,874$ & $-2,874$ & $-2,875$ & $-2,874$ & $-2,875$ & $-2,874$ \\
\hline \multirow{3}{*}{$\begin{array}{c}\text { Primeira } \\
\text { Diferença }\end{array}$} & $\mathrm{ADF}$ & $-11,946$ & $-7,819$ & $-18,182$ & $-15,112$ & $-16,037$ & $-10,791$ & $-12,570$ & $-4,552$ & $-10,243$ \\
\hline & $p$-valor & 0,000 & 0,000 & 0,000 & 0,000 & 0,000 & 0,000 & 0,000 & 0,000 & 0,000 \\
\hline & $\begin{array}{c}\text { crítico } \\
(5 \%)\end{array}$ & $-2,875$ & $-2,875$ & $-2,874$ & $-2,874$ & $-2,874$ & $-2,875$ & $-2,874$ & $-2,875$ & $-2,874$ \\
\hline \multirow{3}{*}{ Logaritmo } & $\mathrm{ADF}$ & $-2,819$ & $-2,132$ & $-1,162$ & $-0,726$ & $-1,473$ & 0,336 & $-1,806$ & 0,056 & 1,964 \\
\hline & $p$-valor & 0,057 & 0,233 & 0,691 & 0,837 & 0,546 & 0,980 & 0,377 & 0,962 & 0,303 \\
\hline & $\begin{array}{l}\text { crítico } \\
(5 \%)\end{array}$ & -2 , & 374 & 4 & -2 & 4 & 5 & 4 & 75 & $-2,875$ \\
\hline \multirow{3}{*}{$\begin{array}{c}\text { Diferença } \\
\text { de } \\
\text { logaritmo }\end{array}$} & $\mathrm{ADF}$ & $-20,965$ & $-20,724$ & $-18,336$ & $-14,974$ & $-14,562$ & $-10,783$ & $-11,962$ & $-4,639$ & $-9,393$ \\
\hline & $p$-valor & 0,000 & 0,000 & 0,000 & 0,000 & 0,000 & 0,000 & 0,000 & 0,000 & 0,000 \\
\hline & $\begin{array}{c}\text { crítico } \\
(5 \%)\end{array}$ & $-2,874$ & $-2,874$ & $-2,874$ & $-2,874$ & $-2,874$ & $-2,875$ & $-2,874$ & $-2,875$ & $-2,875$ \\
\hline
\end{tabular}

Notas: Q_S é a Quantidade Exportada (em quilogramas); PI_B é o Preço Interno do Bovino (em R\$/ kg); PI_F é o Preço Interno do Frango (em R\$/kg); PD_S é o Preço Interno do Suíno (em R\$/kg); PE_B é o Preço Externo do Bovino (em US\$ $\$ \mathrm{~kg}$ ); PE_F é o Preço Externo do Frango (em US\$ $/ \mathrm{kg}$ ); PE_S é o Preço Externo do Suíno (em US\$/kg); R é a Renda representada pelo PIB do Brasil (em milhões de $R \$$ ); e E é a taxa de câmbio em R\$/US\$.

Fonte: Dados da pesquisa (2013).

Com o objetivo de testar a relação de longo prazo, cointegração, entre as variáveis foi aplicado o teste de Engle-Granger. O teste indicou que quando a variável dependente é a quantidade exportada as séries são cointegradas (ver Tabela 2).

Tabela 2. Teste de Engle-Granger para cointegração

\begin{tabular}{c|c|c|c|c}
\hline Dependent & tau-statistic & Prob.* & Z-statistic & Prob.* \\
\hline Q_S & $-8,1625$ & 0,0000 & $-102,4524$ & 0,0000 \\
\hline
\end{tabular}

Notas: * $p$-valores conforme MacKinnon (1996); Q_S é a Quantidade Exportada (em quilogramas). Fonte: Dados da pesquisa (2013).

Green (2002) explica que a cointegração acontece quando séries temporais não estacionárias, mas integradas de mesma ordem, compartilham tendências estocásticas semelhantes, assim, apresentam relação de equilíbrio de longo prazo. 


\subsection{ESTIMAÇÃO COM QUEBRAS ESTRUTURAIS}

Os resultados do teste Bai-Perron apontaram uma quebra estrutural após o mês de fevereiro de 2002 (ver Tabela 3), confirmando o exame visual da Figura 1. Em 2002, o Brasil aumentou suas exportações em 75\% em relação a 2001. Porém, Rocha, Moura e Girotto (2007) afirmam que 2001 foi ano de início de uma crise histórica para a suinocultura. Segundo os autores, os bons resultados das exportações nos anos anteriores impulsionaram o crescimento do rebanho nacional, levando ao significativo aumento da oferta de carne suína. Dados do IBGE (2013) indicam que o aumento dos rebanhos de suínos foi de 3\%, entre 2000 e 2001 e redução de $2 \%$ entre 2001 e 2002, e um aumento dos abates de $14 \%$ e $18 \%$ em 2001 e 2002 , respectivamente.

Tabela 3. Teste de quebras estruturais de Bai-Perron

\begin{tabular}{c|c|c|c}
\hline Break Test & F-statistic & Scaled F-statistic & Critical Value** $^{* *}$ \\
\hline 0 vs. $1^{*}$ & 6,6871 & 66,8706 & 27,03 \\
\hline 1 vs. 2 & 2,8419 & 28,4192 & 29,24 \\
\hline
\end{tabular}

Break dates:

\begin{tabular}{c|c|c|c}
\hline & Sequential & Repartition & \\
\hline 1 & $2002 \mathrm{M} 02$ & $2002 \mathrm{M} 02$ & \\
\hline
\end{tabular}

Fonte: Dados da pesquisa (2013).

Notas: * Significativo em nível de 5\%. **Valores críticos conforme Bai e Perron (2003).

Para Rocha, Moura e Girotto (2007), houve aumento, coincidente, do custo de produção no mesmo ano, levando a redução do número de matrizes e de reprodutores, descapitalizando os produtores. Segundo o Centro de Estudos Avançados em Economia Aplicada, a redução da relação de compra de insumos, milho e farelo de soja, na ordem de $36 \%$ e $31 \%$, respectivamente, entre o primeiro e o segundo semestre de 2002 denota a existência de dificuldades na criação de suínos a partir deste ano (CEPEA, 2003). Apesar destes problemas, as exportações brasileiras após 2002 permaneceram em um nível superior aos anos anteriores, em média 575 mil toneladas do produto. Por sua vez, o período de 1995 a 2001 teve média de 106 mil toneladas, menos de um quinto do período pós quebra. 
Entre diversos fatos que poderiam explicar a quebra estrutural, o Brasil vinha sofrendo influência da crise na Argentina, seu principal parceiro comercial, desde 1993, sendo obrigado a desvalorizar a moeda em 1999 (BLUSTEIN, 2003). Em 2002, o Brasil também passou por mudança de governo. Investidores estrangeiros, receosos com a possível eleição de Luiz Inácio da Silva (Lula), candidato de esquerda, em oposição ao governo corrente, promoveram fuga do capital estrangeiro. Neste ano, o Fundo Monetário Internacional anunciou suporte financeiro de US\$30 bilhões para garantir a estabilidade econômica do Brasil (IMF, 2007).

Confirmando-se que houve quebra estrutural justificada, as estimativas devem ser apresentadas em dois regimes, um antes e outro após a quebra, conforme apresentado na Tabela 4 . Em cada regime diferentes relações entre as variáveis podem ser observadas. Assim, os resultados da equação em $j=1$, correspondente aos resultados da estimação para o primeiro regime e os resultados da equação em $j$ $=2$, à estimação para o segundo regime. Na primeira e sexta colunas da Tabela 4 são apresentados os nomes das variáveis, na segunda e sétima colunas são apresentados os coeficientes, a terceira e oitava colunas mostram o erro padrão, na quarta e nona colunas apresenta-se o teste $t$ e, por fim, na quinta e décima colunas o $p$-valor de cada coeficiente.

Tabela 4. Estimativa de elasticidade da demanda de carne suína por Mínimos Quadrados com Quebras, janeiro de 1995 a junho de 2013

(continua)

\begin{tabular}{|c|c|c|c|c|c|c|c|c|c|}
\hline \multicolumn{5}{|c|}{$\begin{array}{c}\text { 1995M02 - 2002M01 -- } 84 \text { obs } \\
(j=1)\end{array}$} & \multicolumn{5}{|c|}{$\begin{array}{c}2002 \mathrm{M} 02-2013 \mathrm{M} 06--137 \text { obs } \\
(j=2)\end{array}$} \\
\hline Variável & Coef. & $\begin{array}{l}\text { Erro } \\
\text { pad. }\end{array}$ & $t$ & $p$-valor & Variável & Coef. & $\begin{array}{l}\text { Erro } \\
\text { pad. }\end{array}$ & $t$ & $p$-valor \\
\hline $\mathrm{C}$ & 2,9211 & 5,7225 & 0,5105 & 0,6103 & C & 0,9433 & 4,3060 & 0,2191 & 0,8268 \\
\hline LOG(PE_S) & $-0,6796$ & 0,2678 & $-2,5378$ & 0,0119 & LOG(PE_S) & $-0,2269$ & 0,2063 & $-1,0998$ & 0,2727 \\
\hline LOG(PE_B) & $-0,6384$ & 0,3630 & $-1,7586$ & 0,0802 & LOG(PE_B) & $-0,0851$ & 0,1685 & $-0,5050$ & 0,6141 \\
\hline LOG(PE_F) & 0,1569 & 0,2283 & 0,6873 & 0,4927 & LOG(PE_F) & $-0,2998$ & 0,1724 & $-1,7389$ & 0,0836 \\
\hline LOG(PI_S) & $-0,0380$ & 0,2763 & $-0,1374$ & 0,8908 & LOG(PI_S) & 0,1956 & 0,1248 & 1,5675 & 0,1186 \\
\hline LOG(PI_B) & $-1,1571$ & 0,5651 & $-2,0476$ & 0,0419 & LOG(PI_B) & $-0,8619$ & 0,2556 & $-3,3715$ & 0,0009 \\
\hline
\end{tabular}


(conclusão)

\begin{tabular}{cccccccccc} 
LOG(PI_F) & 0,3795 & 0,2333 & 1,6264 & 0,1054 & LOG(PI_F) & $\mathbf{0 , 4 4 6 1}$ & $\mathbf{0 , 2 1 0 2}$ & $\mathbf{2 , 1 2 2 6}$ & $\mathbf{0 , 0 3 5 0}$ \\
LOG(R) & 0,6711 & 0,4512 & 1,4874 & 0,1385 & LOG(R) & $\mathbf{0 , 9 6 9 8}$ & $\mathbf{0 , 3 9 2 0}$ & $\mathbf{2 , 4 7 4 0}$ & $\mathbf{0 , 0 1 4 2}$ \\
LOG(E) & 0,5283 & 0,3200 & 1,6510 & 0,1003 & LOG(E) & $-0,2555$ & 0,1779 & $-1,4364$ & 0,1524 \\
LOG(Q_S(-1)) & $\mathbf{0 , 4 3 7 6}$ & $\mathbf{0 , 1 0 5 3}$ & $\mathbf{4 , 1 5 6 6}$ & $\mathbf{0 , 0 0 0 0}$ & LOG(Q_S(-1)) & $\mathbf{0 , 3 2 8 2}$ & $\mathbf{0 , 0 8 4 1}$ & $\mathbf{3 , 9 0 2 8}$ & $\mathbf{0 , 0 0 0 1}$ \\
\hline
\end{tabular}

Nota: Variável dependente Q_S; Q_S é a Quantidade Exportada (em quilogramas); PI_B é o Preço Interno do Bovino (em R\$/kg); PI_F é o Preço Interno do Frango (em R $\$ / \mathrm{kg}$ ); PD_S é o Preço Interno do Suíno (em R\$/kg); PE_B é o Preço Externo do Bovino (em US\$/kg); PE_F é o Preço Externo do Frango (em US\$/kg); PE_S é o Preço Externo do Suíno (em US\$/kg); R é a Renda representada pelo PIB do Brasil (em milhões de R\$); e E é a taxa de câmbio em R\$/US\$; $R^{2}$ Ajustado 0,9567. Fonte: Dados da pesquisa (2013).

O primeiro regime representou o período entre janeiro de 1995 e janeiro de 2002. Neste regime há relação negativa e significativa entre o preço externo das carnes suínas e sua demanda no mercado internacional. O coeficiente do preço externo da carne suína mostra que, quando o preço é ajustado em $1 \%$, há uma redução de $0,68 \%$ na quantidade demandada, indicando que a carne suína é inelástica no mercado internacional. Os sinais dos coeficientes indicaram que, no mercado externo, a carne suína e bovina são bens complementares, enquanto a carne de frango é um bem substituto. Em sentido oposto, Santana e Ribeiro (2008) verificaram que a carne suína foi complementar à carne de frango e a carne bovina foi substituta da carne suína no Brasil, no período de 1980 a 2006. A complementariedade das carnes pode ser justificada pelo seu consumo conjunto e uso em produtos processados. Os preços externos da carne bovina, internos da carne de frango e a taxa de câmbio tiveram menor significância, indicando que a demanda pela carne suína neste período pouco sofreu interferência destes preços.

$\mathrm{O}$ segundo regime compreendeu o período entre fevereiro de 2002 e junho de 2013. Neste regime, os impactos significativos foram dos preços internos da carne bovina e de frango e, ainda, da renda. Os coeficientes indicam maior impacto do preço interno da carne bovina e, em último, do preço interno da carne de frango, porém, o valor menor que um indica que a carne suína é inelástica em relação às outras carnes. O coeficiente da renda menor que um indica que a carne suína comportou-se como um bem inferior neste regime. A direção dos sinais indica que 
aumentos dos preços internos da carne bovina impactam em redução da exportação de carne suína. Ao contrário, aumentos de preços internos na carne de frango e da renda nacional fazem crescer as exportações de carnes suínas. Isso ocorreu devido a uma espécie de efeito substituição, característica dos bens inferiores. Os preços externos das carnes suína e bovina, bem como o preço interno do suíno e a taxa de câmbio foram as variáveis sem significância estatística.

Apesar dos estudos anteriores não utilizarem quebras estruturais, os resultados apresentados corroboram os de Resende Filho et al. (2012) e Santana e Ribeiro (2008). Resende Filho et al. (2012) estimaram elasticidade preço da carne suína em -0,053 no mercado brasileiro, entre 1975 e 2008 . A elasticidade preço cruzada da carne bovina resultou em coeficiente de 0,069 e da carne de frango 0,121 . Santana e Ribeiro (2008) estimaram a elasticidade-preço da demanda de carnes suínas em -0,045 (não significativo), e pelas elasticidades preços cruzadas com a carne bovina de $-0,151$ (não significativo) e de frango -0,2435 para o Brasil entre 1980 e 2006.

Os resultados encontrados foram semelhantes aos de Resende Filho et al. (2012) no que tange à elasticidade renda, confirmando que a carne suína é um bem inferior. Santana e Ribeiro (2008) estimaram elasticidade renda de 0,4601, concluindo que a carne de suínos tenderia a se tornar um bem de luxo. Ao contrário, Resende Filho et al. (2012) verificaram a elasticidade renda da carne suína de -0,188. Vale lembrar que o período no qual Santana e Ribeiro (2008) e Resende et al. (2012) estimaram períodos diferentes. Apesar destes resultados não serem comparáveis com os do presente estudo, as magnitudes dos valores indicam que os valores apresentados são aceitáveis.

Em termos gerais, os coeficientes menores que um indicam que a demanda por carne suína brasileira no mercado internacional é inelástica em relação ao próprio preço, de forma consistente com os estudos já realizados. Em relação aos preços das carnes bovinas e de frango também apresenta-se inelástica. Somente entre janeiro de 1995 e fevereiro de 2002 a demanda por carne suína apresenta-se elástica no que tange à elasticidade preço cruzada com o preço interno da carne bovina.

Quanto ao ajustamento do modelo, inicialmente, foi estimado sem a variável defasada, porém o valor da estatística Durbin-Watson de 1,4922 indicou a 
presença de autocorrelação. Para corrigir o problema foi acrescentada ao modelo a variável dependente defasada em $t$ - 1 . Ao acrescentar a variável, o valor da estatística Durbin-Watson calculado para a amostra passou a ser 2,0581, indicando ausência de autocorrelação. $\mathrm{O}$ teste de White rejeita a hipótese de heterocedasticidade ( $F=$ $1,717973, p$-valor 0,005$)$. O coeficiente de determinação ajustado ( $\mathrm{R}^{2}$ ajustado) foi de $95,67 \%$, indicando alto poder explicativo do modelo.

\section{CONCLUSÕES}

O objetivo principal consistiu em verificar o impacto dos preços e da renda na demanda internacional de carne de suínos do Brasil, no período sequente a estabilização de preços. Para isso foi empregado o modelo de Mínimos Quadrados com Quebras. Os resultados do teste de Bai-Perron apontaram uma quebra estrutural a partir de fevereiro de 2002. A quebra foi causada pela crise financeira sofrida pelos produtores de suínos por conta do aumento na quantidade exportada, e consequente aumento na oferta do produto e do seguido aumento dos custos dos principais insumos - milho e soja. Porém, no regime pós quebra o nível das exportações, em toneladas, ficou muito acima do anterior.

No período anterior à quebra, a demanda internacional de carne suína era determinada pelo preço externo da carne suína e pelo preço interno da carne bovina, sendo um período de consolidação da exportação da carne suína. Após a quebra os determinantes passaram a ser os preços internos da carne bovina e de frango e a renda nacional, período em que o Brasil experimentou aumentos sucessivos do PIB. A direção do sinal indicou que a carne suína comportou-se como um bem complementar da carne bovina e substituta da carne de frango no mercado internacional.

Pode-se concluir com estes resultados que a elasticidade da demanda se modifica ao longo do tempo em termos de coeficiente e variáveis de influência. Porém, em comum em todos os períodos, pode-se inferir que a demanda da carne de suínos é inelástica em relação ao próprio preço. Com relação aos preços cruzados, excetua-se o período de janeiro de 1995 a fevereiro de 2012, quando a elasticidade 
preço cruzada da carne de bovinos apresentou-se maior que um, sendo considerada elástica neste período e inelástica nos demais. Quanto à renda, verificou-se que a carne suína brasileira foi um bem inferior em ambos os regimes.

Apesar dos resultados coerentes e representativos, existem algumas limitações quanto à pesquisa. A principal delas conta dos preços informados pelo banco de dados do MDIC, que são em dólares, desconsiderando o frete de destino (Free On Board - FOB). O frete é uma variável não disponível para acesso em bancos públicos. Sugere-se que, em futuras pesquisas, seja acrescentada esta informação nos preços para aumentar a acurácia do modelo e, ainda, utilizar diferentes modelos para comparar os resultados.

\section{REFERÊNCIAS}

ABIPECS. Associação Brasileira da Indústria Produtora e Exportadora de Carne Suína. Carne suína brasileira: nutrientes, 2013. Disponivel em: <http://www. carnesuinabrasileira.org.br/nutrientes.html> . Acesso em: 04 set. 2013.

BAI, J.; PERRON, P. Estimating and Testing Linear Models with Multiple Structural Changes. Econometrica, v. 66, n. 1, jan. 1998. p. 47-78.

BAI, J.; PERRON, P. Computation and analysis of multiple structural change models. Journal of Apllied Economics, v. 18, n. 1, 2003. p. 1-22.

BARROS, G. S. D. C.; BACCHI, M. R. P.; BURNQUIST, H. L. Estimação de equações de oferta de exportação de produtos agropecuários para o Brasil (1992/2000): texto para discussão n. 865. Instituto de Pesquisa Econômica Aplicada, mar 2002. Disponivel em: <http://www.ipea.gov.br/portal/index.php?option=com content\&view $=$ article\&id $=4408>$. Acesso em: 20 set. 2013 .

BLUSTEIN, P. Argentina Didn't Fall on Its Own. The Washington Post, 3 ago. 2003. p. A01. 
CEPEA. Centro de Estudos Avançados em Economia Aplicada. Releases: Dificuldades na suinocultura em 2002 geram incertezas para 2003, 2003. Disponivel em: <http:// cepea.esalq.usp.br/imprensa/?page $=339 \&$ search $=1>$. Acesso em: 18 nov. 2013 .

DURBIN, J.; WATSON, G. S. Testing for Serial Correlation in Least Squares Regression: I. Biometrika, v. 37, n. 3/4, dec. 1950. p. 409-428.

DURBIN, J.; WATSON, G. S. Testing for Serial Correlation in Least Squares Regression. II. Biometrika, v. 38, n. 1/2, jun. 1951. p. 159-177.

ENGLE, R. F.; GRANGER, C. W.J. Co-Integration and Error Correction: Representation, Estimation, and Testing. Econometrica, v. 55, n. 2, mar. 1987. p. 251-276.

FAO. Food and Agriculture Organization of the United Nation. FAOSTAT, 2013. Disponível em: < http://faostat3.fao.org/> Acesso em: 04 set. 2013.

FERGUSON, C. E. Microeconomia. Rio de Janeiro: Forense, 1989.

GALLET, C. A. The income elasticity of meat: a meta-analysis. The Australian Journal of Agricultural and Resource Economics, n. 54, 2010. p. 477-490.

GALLET, C. A. A Meta-Analysis of the price elasticity of meat: evidence of regional differences. Business and Economic Research, v. 2, n. 2, 2012. p. 14-25.

GERVASIO, E. W. Suinocultura - Análise da Conjuntura Agropecuária: SEAB - Secretaria de Estado da Agricultura e do Abastecimento do Paraná, 2013. Disponivel em: < http://www.agricultura.pr.gov.br/arquivos/File/deral/Prognosticos/ SuinoCultura_2012_2013.pdf > . Acesso em: 27 set. 2013.

GREENE, W. H. Econometric analysis. 5. ed. New Jersey: Prentice Hall, 2002.

GUJARATI, D. N.; PORTER, D. C. Econometria básica. $5^{\mathrm{a}}$ ed. Porto Alegre: McGraw Hill, 2011. 
and Trade: Beef, Pork, and Poultry. American Agricultural Economics Association Organized Symposium. Portland, Oregon. 2007.

HOVHANNISYAN, V.; GOULD, B. W. Quantifying the Structure of Food Demand in China Using a Generalized Quadratic AIDS Specification. Southern Agricultural Economics Association Annual Meeting, Orlando, 6-9 fev. 2010.

HUPKOVÁ, D.; BIELIK, P. Estimating Demand Elasticities of Meat Demand in Slovakia. 113th EAAE Seminar "A resilient European food industry and food chain in a challenging world", Chania, Crete, Greece, 3-6 set. 2009.

IBGE. Instituto Brasileiro de Geografia e Estatística. Sistema IBGE de Recuperação Automática de dados - SIDRA, 2013. Disponivel em: < http://www.sidra.ibge.gov. br/>. Acesso em: 02 set. 2013.

IMF. International Monetary Fund. Brazil: Helping Calm Financial Markets, 2007. Disponível em: < http://www.imf.org/external/np/exr/articles/2007/112107.htm>. Acesso em: 17 jan. 2014.

IPEA. Instituto de Pesquisa Econômica Aplicada. Ipeadata, 2013. Disponível em: <http://www.ipeadata.gov.br/>. Acesso em: 20 set. 2013.

KRUGMAN, P. R.; OBSTFELD, M. International economics: theory and policy. 6 . ed. Boston: Pearson Education, 2001.

MACKINNON, J. G. Numerical distribution funcions for unit root and cointegration tests. Journal of Applied Econometrics, v. 11, 1996. p. 601-618.

MDIC. Ministério do Desenvolvimento, Indústria e Comércio Exterior. Exportação brasileira. Aliceweb, 2013. Disponivel em: < http://aliceweb.desenvolvimento.gov. br/>. Acesso em: 02 set. 2013.

PINDICK, R. S.; RUBINFELD, D. L. Microeconomia. 6. ed. São Paulo: Pearson Prentice Hall, 2006. 
RESENDE FILHO, M. D. A. et al. Sistemas de equações de demanda por carnes no Brasil: especificação e estimação. Rev. Econ. Sociol. Rural [online], v. 1, jan./mar. 2012. p. 33-50.

RG NUTRI. Saúde e qualidade de vida: carne vermelha versus carne branca, 2013. Disponível em: <http://www.rgnutri.com.br/sqv/saude/crcb.php > . Acesso em: 04 set. 2013.

ROCHA, D. T. D.; MOURA, A. D. D.; GIROTTO, A. F. Análise de risco de sistemas de produção de suínos, integrado e independente, em períodos de alta e baixa rentabilidade. Brazilian Review of Economics and Agribusiness, v. 5, n. 3, 2007. p. $400-423$.

SANTANA, A. C.; RIBEIRO, D. T. Sistema de demanda de carnes no Brasil: modelo de equação aparentemente não-relacionada. CONGRESSO DA SOCIEDADE BRASILEIRA DE ECONOMIA, ADMINITRAÇÃO E SOCIOLOGIA RURAL (SOBER), 46., 2008, Rio Branco. Anais... Rio Branco, AC: SOBER, 2008.

VALLE, E. R. Carne bovina: alimento indispensável. Embrapa Gado de Corte Divulga, Campo Grande, MS, n. 41, 2000. Disponível em: http://www.cnpgc. embrapa.br/publicacoes/divulga/GCD41.html. Acesso em: 04 set. 2013.

VARIAN, H. R. Intermediate microeconomics. 8. ed. New York-London: W. W. Norton \& Company, 2010.

WHITE, H. A Heteroskedasticity-Consistent Covariance Matrix Estimator and a Direct Test for Heteroskedasticity. Econometrica, v. 48, n. 4, may. 1980. p. 817-838.

Recebido em: 21 de março de 2014 Aceito em: 20 de maio de 2015 